Annals of Glaciology 41983

(c) International Glaciological Society

\title{
SNOW AND SLUSH ON FLOATING LAKE ICE
}

\author{
by
}

\author{
Hans Röthlisberger \\ (Versuchsanstalt für Wasserbau, Hydrologie und Glaziologie, ETH-Zentrum, CH-8092 Zürich, \\ Switzerland)
}

\section{ABSTRACT}

The behaviour of a floating sheet of lake ice was investigated for the case when it becomes loaded by a layer of fresh snow which is later soaked with water. This latter condition interferes with the traditional horse races of St Moritz, which are held on the lake each year. A piezometric precision gauge which measures accurately the vertical movements of the floating ice relative to the free surface of the lake is described. The level of the lake, in turn, oscillates, depending on the use of water by the local power company. Detailed measurements from the winter of 197879 are presented, showing that the piezometric level rises in direct response to precipitation, and that it rises further when the snow becomes soaked with water. With a simple model it is shown that the ultimate level is a function of the snow density, and it is concluded that immediate compaction of falling snow is an appropriate measure to reduce the amount of water entering the snow. It is very unlikely that the oscillations of the level of the lake caused by the demands of the power company have an influence on the slush problem.

\section{INTRODUCTION}

Sporting activities at the famous Alpine resort of St Moritz include horse races, which are usually held in February on the frozen lake. Both the race track and stands for the spectators are prepared and erected on the ice. Since the lake (Lej da S Murezzan) is located at the relatively high altitude of $1768 \mathrm{~m}$ a.s.1. in the Engadin, which is a flat, wide, open valley representing a basin of cold air, a sufficient thickness of ice is hardly ever a problem, but if much snow falls at the time of preparation of the track, or during the races proper, an inflow of water into the snow cover on top of the ice can become such a serious obstacle that the races may have to be cancelled.

The lake at St Moritz not only serves the organizers of the races, but also the local power company. Water of the river Inn which feeds and drains the lake is stored in the lake mainly at night to be used up during the day at peak hours of consumption. This causes the level of the lake to fluctuate, and those responsible for the preparation of the race tracks tend to blame these fluctuations and, hence, the power company for their troubles with the slush.

In 1936, the races had to be cancelled on the occasion of their 25 th anniversary. The climatic conditions that led to the water-logging of the race tracks was investigated by Lütschg-Loetscher and others (1954). In an extensive study, which continued for many years and included many aspects of lake ice and climate, they showed that snowfall is one of the main factors in water seepage, not the fluctuations of the water level.

On behalf of the authorities of the town of St Moritz and after serious problems with the races in 1975, our laboratory proposed and helped to carry out investigations to measure further the influence of fluctuations of the level of the lake on the formation of slush. A first set of measurements from 31 January to 29 March 1976 was inconclusive because of lack of snow, but during the winter of 1978-79 inore interesting conditions with various snowfalls were encountered.

\section{PIEZOMETRIC GAUGE}

Lütschg-Loetscher and others (1954) have shown by optical levelling from the shore that within the accuracy of their observation, which amounted to a few millimetres, the floating sheet of lake ice followed the fluctuations of the lake, with the exception of a narrow margin of a few metres where the influence of grounding was felt: here, when it had time to freeze to the ground, the ice became flooded when the water level rose again. Flooding of the ice was otherwise caused directly by rainfali or by melting (rather rare at the height of winter in the Engadin) or, more commonly, by an overload of snow, combined with the penetration of lake water to the surface through cracks or holes in the ice. In order to ineasure the free level of the lake relative to the ice cover, holes were drilled through the ice at the centre of a metal cylinder which was either frozen to the surface of the ice under cold, dry conditions or sealed with a rubber gasket when the surface was wet (Lütschg-Loetscher and others 1954: fig.38).

Although the overwhelming importance of the weather in the formation of slush on the ice was, in principle, demonstrated by Lütschg-Loetscher and his co-workers, it was nevertheless felt that there might be some second-order effect from the fluctuations in water level, which would cause horizontal stresses in the ice cover grounded on the sloping shores. A new investigation was therefore proposed and carried out, based on a more accurate technique for measuring the free level of the lake relative to the ice cover with a special gauge.

The gauge is shown schematically in Figure 1 . It consists essentially of a pipe containing a nonfreezing liquid, the level of which is measured. A rubber balloon keeps the liquid from mixing with the lake water. It is only partly filled, so that it stays completely slack. The pressure at the inside is then exactly the same as that on the outside, but the 


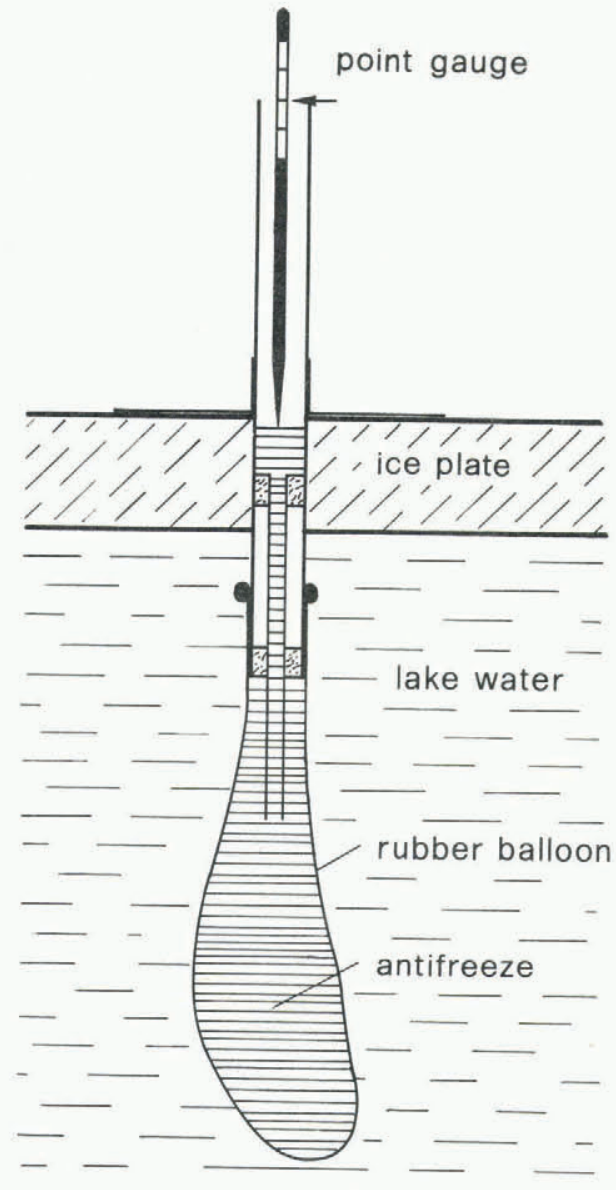

Fig.1. Piezometric gauge on floating lake ice.

balloon nevertheless contains sufficient liquid to fill the pipe when the ice becomes loaded down by snow. We have used diluted antifreeze (ethylene glycol) as a liquid, al though it is slightly heavier than water. This did not matter as we were concerned with fluctuations of the level with time rather than with the absolute position of the level of the lake. The density difference should nevertheless not be too large, otherwise the balloon becomes stretched. The hydraulic connection from the upper part of the pipe to the balloon is reduced in size in order to maintain a low rate of heat exchange; otherwise the balloon might be cooled down by convection, resulting in the formation of ice around $i t$.

The pipe is inserted into a closely fitting hole at an early stage of ice formation when the ice cover is sufficiently cold for the pipe to freeze solidly to the ice. A metal plate fixed to the pipe is also frozen to the ice. This serves a dual purpose: first$l y$, if the ice is already loaded with snow, so that water tends to flow out, it is usually possible to seal the flow by spreading slush between the plate and the ice surface and pressing down; secondly, the plate will maintain the pipe at a fixed level, should it become loose when the ice becomes temperate at a later stage.

For the piezometric measurement in the pipe we have used a point gauge with an electronic switch, devised by the hydraulics section of our laboratory, which allows the position of the surface of the liquid to be read to within $0.1 \mathrm{~mm}$ on a Vernier scale. Repeated readings have usually been within 0.1 or $0.2 \mathrm{~mm}$. However, since we have not controlled the temperature of the liquid, somewhat larger errors may occur, also because of bending and cracking of the ice due to thermal stresses. We have nevertheless measured temperatures at the outside of the pipe in our first set of experiments in 1976, but have not observed any systematic effect, and henceforth we have dispensed with temperature measurements on the ice; air temperatures, however, were available from the weather station of the meteorological office at St Moritz.

\section{EXPERIMENTAL RESULTS}

The winter season of 1978-79 turned out to be almost ideal for the planned experiments, as dry cold periods alternated with periods of heavy snowfall combined with high air temperatures. Once again the racing programme was impaired by the presence of water-soaked snow on the ice. Typical ice conditions are listed in Table I.

TABLE I. LAKE AT ST MORITZ: ICE CONDITIONS IN WINTER 1978-79
Date

\section{Ice thick- ness $\left(h_{j}\right)$}

(m)

0.20

$15 \mathrm{Dec} 78$

28 Dec 78

29 Jan 79

19 Feb 79

19 Mar 79

30 Mar 79
0.22

0.45

0.50

0.55

\section{Depth of} watersoaked snow ( hw
Snow depth Total snow above ice depth $\left(h_{\mathrm{s}}\right)$ or water

$\begin{array}{cc}-\overline{10} & 0.03 \\ - & 0.10 \\ 0.20 & 0.55 \\ 0.10 & 0.30 \\ 0.10 & 0.40 \\ & 0.40\end{array}$

0.20

0.65

0.50

0.50
The lake is small and elongated, being some $1.7 \mathrm{~km}$ long, up to $580 \mathrm{~m}$ wide and up to $44 \mathrm{~m}$ deep. The horse races take place on its western half. On 15 December 1978 four piezometric gauges were installed in the ice. Gauge 1 was located near the open water at the mouth of the river Inn, gauges 2 and 3 in the middle of the lake inside the oval race track (where there was little disturbance), and gauge 4 some $50 \mathrm{~m}$ from the shore beside the on-ice parking 1ot. Readings were taken from 18 December 1978 till 19 March 1979 once or twice per day at 0930 and/or 1630, at intervals of occasionally one day, but usually two days or more. The results of the piezometric level changes are shown in Figure 2 together with the fluctuations in the level of the lake, air temperature and precipitation.

The main feature of the results is the tendency of the piezometric measurements of lake levels to remain almost constant at certain times, but to rise markedly at others. The strong upward movement is related to the periods of heavy precipitation rather than to changes in the level of the lake or the temperature. Although eventually the different gauges rise by approximately the same amount, a remarkable difference with time occurs as well as a general time lag. This behaviour, in particular the time lag for piezometric rise following snowfall, will be explained in the next section.

During the three periods least affected by precipitation, from 18 to 22 December 1978,3 to 8 January 1979 and 12 to 26 January 1979 , only minor piezometric level changes of the order of a few millimetres were measured (with one exception where the change exceeded $10 \mathrm{~mm})$; changes in the 1 evel of the lake amounted to 90,180 and $130 \mathrm{~mm}$ during the three respective periods. Examples of the observed piezometric fluctuations are given in Table II together with the changes of level of the lake. No obvious correlation can be noticed.

SNOW LOAD, PIEZOMETRIC WATER LEVEL AND POTENTIAL WATER SATURATION

The very strong piezometric rise lasting for several days after a heavy snowfall was a surprise to us, but was not difficult to explain after it had been observed. It is due to water seepage into the snow and means simply that this water has to be regarded as an additional load on the floating ice. 


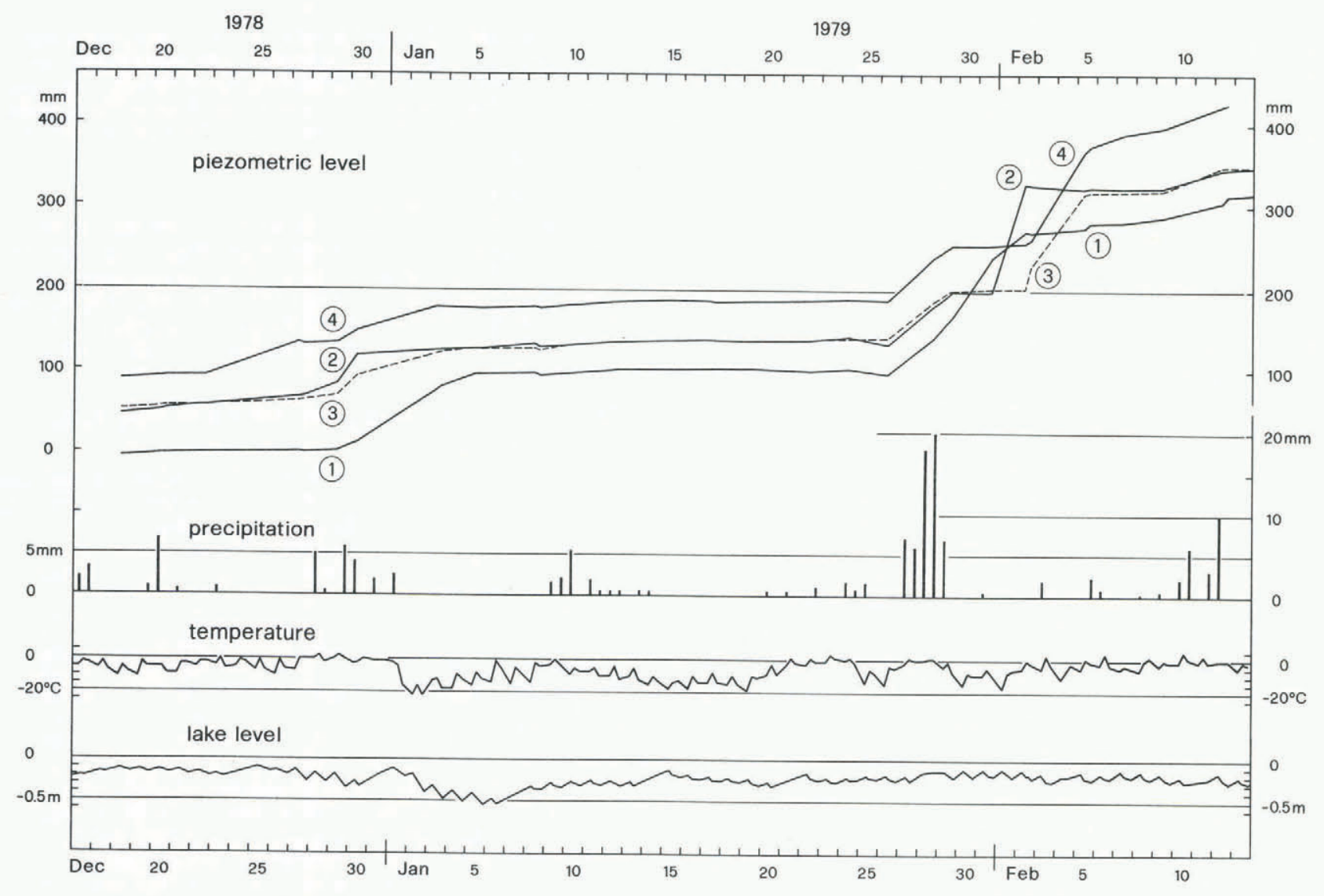

Fig.2. Fluctuations with time of (from top to bottom) the piezometric levels of four gauges on the floating ice on the lake at St Moritz, precipitation and temperature at the St Moritz weather station (1 $825 \mathrm{~m} \mathrm{a.s.1.),}$ and the fluctuations of the level of the lake at the limnigraph station of the power company in the winter of 1978-79. For the piezometric and lake levels the zero line represents an arbitrary reference level, which is different in each case.

TABLE II. CHANGES IN LEVELS OF LAKE AND PIEZOMETER LEVELS (a11 measurements in $\mathrm{mm}$ )

\begin{tabular}{|c|c|c|c|c|c|}
\hline \multirow[b]{2}{*}{$\begin{array}{l}\text { Time } \\
\text { interval }\end{array}$} & \multirow[b]{2}{*}{$\begin{array}{c}\text { Change in } \\
\text { level of } \\
\text { lake }\end{array}$} & \multicolumn{4}{|c|}{ Change in level of gauges } \\
\hline & & 1 & 2 & 3 & 4 \\
\hline $\begin{array}{l}5 \mathrm{Jan} 1979 \\
0930 \text { to } 1630\end{array}$ & -80 & +0.7 & -0.7 & +0.1 & -0.9 \\
\hline $\begin{array}{l}5 \text { to } 8 \mathrm{~J} \text { an } 1979 \\
1630 \text { to } 0930\end{array}$ & +180 & -0.5 & +0.9 & +6.0 & +2.9 \\
\hline $\begin{array}{l}8 \mathrm{~J} \text { an } 1979 \\
0930 \text { to } 1630\end{array}$ & -30 & -2.7 & -1.8 & -4.4 & -2.7 \\
\hline $\begin{array}{l}15 \text { to } 17 \mathrm{~J} \text { an } 1979 \\
0930 \text { to } 0930\end{array}$ & -70 & +0.9 & +0.3 & +1.1 & -1.0 \\
\hline $\begin{array}{l}17 \mathrm{~J} \text { an } 1979 \\
0930 \text { to } 1630\end{array}$ & -30 & +0.1 & -0.7 & -0.3 & -0.5 \\
\hline $\begin{array}{l}17 \text { to } 19 \mathrm{~J} \text { an } 1979 \\
1630 \text { to } 0930\end{array}$ & 0 & -0.4 & -0.5 & -1.0 & +0.7 \\
\hline
\end{tabular}

A simplified model serves to explain the effect of ice thickness and snow and water seepage on the piezometric level. In this model we assume pure ice without any bubbles, snow of uniform density, and complete saturation in that part of the snow which becomes soaked with water. The various situations that can now exist are illustrated in Figure 3 . The height of the piezometric level above the base of the lake ice $h_{p}$ is found in each case by equating the pressure of the water column with the weight per unit area of the ice plus the overlying layers. For ice alone (Fig.3(a)) we obtain

$$
h_{p}=\frac{\rho_{i}}{\rho_{w}} h_{i}=0.92 h_{i}
$$

where $h$ is thickness, $p$ density, $i$ ice and $w$ water. In the next case of ice and dry snow (Fig.3(b)), we obtain

$$
\rho_{w} h_{p}=\rho_{j} h_{j}+\rho_{s} h_{s}
$$

where $s$ is snow.

The piezometric level stands above the surface of the ice if $\rho_{S} h_{S}>0.08 \rho_{w} h_{j}$, and water can seep into the snow if there is a leakage in the ice. Let us now assume that water has filled a layer of snow of thickness $h_{w}$. This is the most general case (Fig.3(c)), for which the pressure balance is given by

$$
\rho_{w} h_{p}=\rho_{i} h_{j}+\rho_{s} h_{s}+\rho_{w} h_{w}\left(1-\frac{\rho_{s}}{\rho_{i}}\right) .
$$

From Equation (3), it follows that $h_{p}$ increases with $h_{w}$; therefore seepage continues, but this is only the case as long as $h_{p}>h_{j}+h_{w}$. The equilibrium is reached when $h_{p}=h_{j}+h_{w}$, i.e. When the potential 


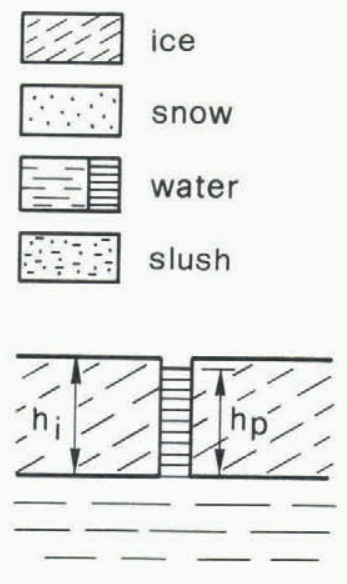

a. no snow

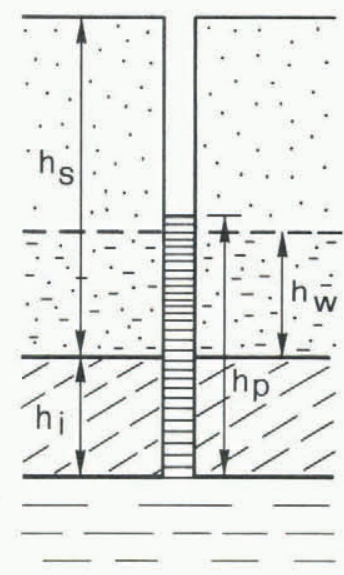

c. snow partly saturated

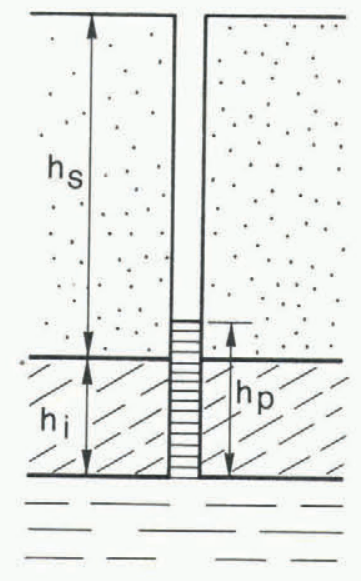

b. dry snow

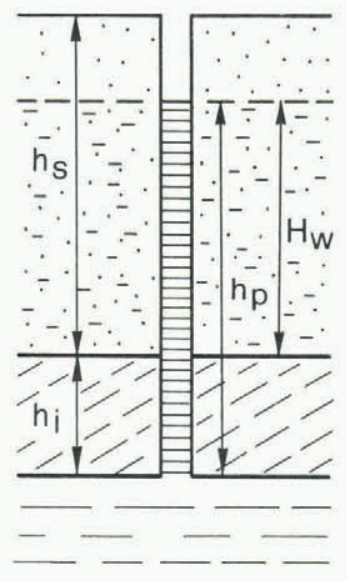

d. potential saturation

Fig.3(a to d). Model cases of floating lake ice for various conditions of snow cover and slush.

saturation of the snow is reached (Fig.3(d)). The ultimate thickness of the water layer $\mathrm{H}_{\mathrm{w}}$ is

$$
H_{w}=\frac{\rho_{i}}{\rho_{W}} h_{s}-\frac{\rho_{i}}{\rho_{S}} h_{i}\left(1-\frac{\rho_{i}}{\rho_{W}}\right),
$$

or

$$
H_{w}=0.92 h_{S}-0.07 \frac{h_{i}}{\rho_{S}} \text {, }
$$

where $\rho_{\mathrm{s}}$ is measured in $\mathrm{Mg} \mathrm{m}^{-3}$. For a snowfall of a given water equivalent $N$ we can replace the density $\rho_{S}$ by $\mathrm{N} / \mathrm{h}_{\mathrm{S}}$. Inserting this expression in Equation (4) gives

$$
H_{W}=\left[\frac{\rho_{i}}{\rho_{W}}-\frac{\rho_{i}}{N}\left(1-\frac{\rho_{i}}{\rho_{W}}\right) h_{i}\right] h_{S} .
$$

This means that the potential thickness of the watersoaked layer is proportional to the snow depth for each particular snowfall.

The model does not account for air being entrapped in slush and bubbly ice forming when slush becomes frozen, nor for the fact that water may rise higher than $\mathrm{H}_{W}$ owing to capillary action. The two effects have opposite signs.

\section{INTERPRETATION OF THE PIEZOMETRIC MEASUREMENTS}

It is now easy to explain the rise of the piezometric readings following snowfall. In the case when the snow remained dry (and the ice thickness remained constant), the added weight of precipitation was directly reflected in the piezometer reading: the change of the piezometer level in $\mathrm{mm}$ was equal to the precipitation in $\mathrm{mm}$ of water. The best example is the snowfall from 26 to 29 January 1979. For that period, precipitation at the meteorological station amounted to $57.6 \mathrm{~mm}$ and the piezometric level changed by 64.0 , $59.5,55.6$ and $62.0 \mathrm{~mm}$ at the four gauges. Gauge 1 had already started a steeper rise (attributable to flooding), while the mean of the three remaining gauges amounted to $59.0 \mathrm{~mm}$. The differences between the individual gauges as well as those between piezometric and precipitation measurements may well have been real.

The initial rise occurred simultaneously with the deposition of snow or other precipitation; sooner or later it was followed by an additional rise caused by the water seepage into the snow. While precipitation affected all gauges alike, seepage differed from place to place. This explains why at the end of January the curves of piezometric level shown in Figure 2 are almost parallel to each other during the initial phase, but diverge conspicuously later on. After 5 February, gauges 1,2 and 3 behaved similarly again. A divergence of the lines is a clear indication that water seepage has set in, whereby it is more intense the steeper the line becomes. In the case of the heavy precipitations, at the end of January, seepage was not recorded at most of the gauges until the precipitation had completely ceased, while, at the end of December, flooding began much sooner. It lasted for many days in both cases, so that we can conclude that seepage is in general a slow process.

During the entire period of almost two months shown in Figure 2 , gauges 2 and 3 showed almost identical behaviour apart from the transitory stages during flooding. The traces for gauges 1 and 4 are drawn below and above the other two lines, respectively. These differences reflect that the position of the zero levels of each gauge, relative to the ice, has been chosen arbitrarily. The traces can therefore be shifted arbitrarily up or down, parallel to themselves, and an almost equally close fit would result between any other combination of gauges as the one illustrated to exist between gauges 2 and 3 . The close resemblance of the traces to each other indicates that ice thickness, amount of snowfall, snow density, final water saturation and refreezing were probably very similar at all points.

The daily fluctuations of the piezometric levels are very small (in Table II over half of the listed changes stay below $1 \mathrm{~mm}$ ). It is concluded that bending of the ice sheet, which might occur if the daily fluctuations in the level of the lake caused horizontal stresses, is negligible. This finding does not preclude the presence of such stresses. A tensile stress in particular would not cause the ice to bend, but might open up pre-existing cracks (or even cause cracks to form). This in turn would affect the slush formation. Readings during slush conditions were not detailed enough to show any cyclic effect on seepage, should it exist. In order to answer that question, a more elaborate survey including the detailed observation of cracks where water intrudes into the snow would be needed.

For a full understanding of seepage, it is important to know by which means the water has access to a given area of the ice cover, and how quickly it can spread. In principle, water can pass through the ice in the following ways: (i) through cracks formed by temperature changes; this is a mechanism which is more likely to occur at the first heavy snowfall than later on, because temperature fluctuations are reduced once an insulating snow layer has developed, 
(ii) through veins at grain boundaries after the ice has remained at $0^{\circ} \mathrm{C}$ for an extended period of time, following for instance a melt period with rain, ( $i i i$ ) through unfrozen holes in places where vertical convection in the lake occurs, caused by ascending gases (methane) or an inflow of warm spring water (sometimes also releasing gases), (iv) from the shore where open water may exist at the mouths of rivers or at the inflow of sewage water, and $(v)$ from the shore where the ice is most likely to break when the lake level fluctuates, for natural or artificial reasons. From statements made by the person who is responsible for the preparation of the race track, it seems that when conditions become critical, water has access to the ice surface in different places and by different ways, including water holes developing in a particular location (gases?), but inflow from the shore is probably not the rule. This is partly corroborated by the measurements, since the ice at the site of gauge 4 near the lake shore was one of the last gauges to become affected at the beginning of February; at the end of December, on the contrary, it appears to have been saturated before the others (which still does not mean that the water was spreading all the way from the shore to the interior of the lake).

Although the investigations have not provided any direct evidence for the effect of changes in the level of the lake on slush formation, this question cannot be completely answered. For practical purposes, however, it can be concluded that keeping the level of the lake stable might perhaps delay water seepage under certain conditions, but would not usually prevent the later formation of slush.

\section{RECOMMENDED MEASURES}

Our investigations were intended to show which factors played a decisive role in slush formation, and to recommend how to deal with the problem when conditions become difficult for the preparation of the race track. The measurements first of all confirmed the earlier conclusion by Lütschg-Loetscher and others (1954) that heavy snowfall combined with high temperature are primarily to blame for water seepage into the snow. The action that should be taken to cope with the problem follows readily from Equation (5). Since for a given snowfall the potential thickness of the saturated layer is directly proportional to the thickness $h_{S}$ of the snow layer, the most efficient way to reduce the amount of water above the ice is to compact the snow. This should be done as quickly and as efficiently as possible, preferably as soon as the snow starts to fall. In this way the amount of water that can seep into the snow can be reduced significantly, because not only is the thickness of the water-saturated layer reduced, but so also is the water content of the slush. The chances that the slush layer will freeze again are thus strongly increased. Once the slush is frozen it becomes part of the ice layer, increasing the bearing capacity for new snow which may fall later (exactly what. happened in January, as evident in Table I from the disappearance of water and increase of ice thickness between 28 December 1978 and 29 January 1979). Note that frozen slush has a higher bearing capacity than clear ice because of $i$ ts bubble content.

An alternative solution would be to spray the snow with water in order to compact it; this would first of all reduce the insulating effect of the snow and thereby facilitate the freezing of the slush. Both solutions, and this latter one in particular, depend on sufficiently cold weather for the successful preparation of the race track after flooding.

\section{ACKNOWLEDGMENTS}

The author wishes to thank Mr Pietro Baracchi, surveyor of the town of St Moritz, and his colleagues for carrying out the measurements, and the Mayor's office for allowing the data to be used in this publication. Limnigraph copies have kindly been supplied by the St Moritz power company. Further thanks are due to $\mathrm{Mr}$ Paul Gnos for his mechanical skill in developing the gauge and to $\mathrm{Dr}$ Wilfried Haeberli for the supervision of the first experiments with the gauges in 1976 .

\section{REFERENCES}

Lütschg-Loetscher 0, Hauck T, Bohner R 1954 Die Eis- und Schneeverhältnisse der Oberengadiner Seen, insbesondere des St.. Moritzer Sees. Beiträge zur Geologie der Schweiz. Geotechnische Serie. Hydrologie 4. (This is the 10 th chapter, separately paginated and published, of Zum Wasserhaushalt des Schweizer Hochgebirges, Vol 1, Part 3. Zürich, Schweizerische Geotechnische Kommission) 